\title{
The roles of the insulin-like growth factor system and leptin as possible mediators of the effects of nutritional restriction on age at puberty and compensatory growth in dairy heifers
}

\author{
G. Luna-Pinto ${ }^{1}$ and P.B. Cronjé $e^{2}$ \\ Department of Animal and Wildlife Sciences, University of Pretoria, Pretoria 0002, South Africa
}

\begin{abstract}
The aim of this experiment was to determine to what extent changes in the blood concentrations of insulinlike growth factor-1 (IGF-1), IGF binding proteins (IGFBPs), leptin and glucose are associated with compensatory growth and age at puberty in Friesian heifers. Twelve heifers (6 months old; $179.8 \mathrm{~kg}$ body weight) were allocated to one of two dietary treatments for 30 weeks. Treatments were designed to result in two different growth rates during the first 13 weeks of the experiment, viz. $0.3 \mathrm{~kg} / \mathrm{d}$ (restriction treatment) or $0.6 \mathrm{~kg} / \mathrm{d}$ (control treatment). From week 14 to 30, the restricted group received the same amount of feed per kg bodyweight as was fed to the control group (compensatory phase). Heifers in the control treatment reached puberty four weeks earlier than the restricted group. Mean body weight at puberty was $256.3 \mathrm{~kg}$ and was not affected by treatment. During the compensatory phase, the growth rate of the previously restricted animals was greater, and feed conversion ratio superior, compared to that of the control group. Plasma IGF-1 and IGFBP-3 concentrations were higher in the restricted group than in the control group during the early compensatory phase. Concentrations of IGFBP-3 increased and peaked at puberty for both treatments, even though puberty occurred at different ages. In contrast, concentrations of IGF-1 peaked at the point of maximum growth rate in the previously restricted animals, and in neither treatment was there a clear relationship with the age of puberty. Plasma leptin concentrations increased until puberty in both treatments even though the date of puberty differed. Plasma glucose concentration did not change at puberty for either treatment; however, differences between treatments were found after the restriction period. There were no differences in IGFBP-2 concentrations between treatments or sampling periods. It is concluded that concentrations of glucose, IGF-1 and IGFBP-3 are affected by nutritional restriction and repletion, and may contribute in some measure to the endocrine regulation of compensatory growth. It is suggested that the increased concentrations of leptin and IGFBP-3 during pubertal development may act as physiological signals for the onset of puberty.
\end{abstract}

Keywords: IGF, leptin, puberty, compensatory growth, heifers, ruminant, nutrition

${ }^{1}$ Present address: San Lorenzo 566 - 12 "A", CP: 5000 - Cordoba, Argentina

${ }^{2}$ Author to whom correspondence should be addressed. E-mail: pbcronje@ postino.up.ac.za

\section{Introduction}

The controlled growth and development of prepubertal females to conceive at an early age is an important aspect of all livestock production systems, but is particularly important for dairy production systems. A high plane of nutrition post-weaning will result in early puberty in heifers (Buskirk et al., 1995), but growth rates greater than $700 \mathrm{~g} / \mathrm{d}$ may compromise later milk yield (Sejrsen et al., 1982). The reason for this reduction in future performance is that the accompanying adipose tissue deposition in the mammary gland impairs the development of milk secretory cells (Sejrsen et al., 1982). A high growth rate may also result in greater weights of internal organs in relation to body weight, which in turn may increase metabolic rate and hence maintenance nutrient requirements per unit body weight (Koong et al., 1982). On the other hand, low growth rates during the growing phase typically delay the attainment of puberty and increase the unproductive period. Despite the importance of the association between nutrition and reproductive activity, the endocrine signals that are involved in regulating the onset of puberty remain poorly understood. The aim of this experiment was to study how changes in the blood concentrations of insulin-like growth factor-1 (IGF-1), IGF binding proteins (IGFBPs), leptin and glucose mediate the effects of food restriction and compensatory growth on the age at puberty in Friesian heifers. 


\section{Material and methods}

Twelve Friesian heifers ( 6 months old; $179.8 \pm 6 \mathrm{~kg}$ body weight (mean \pm s.e.m.)) were allocated to one of two dietary treatments for 30 weeks. Treatments were designed to result in two different growth rates during the first 13 weeks of the experiment, viz. $0.3 \mathrm{~kg} / \mathrm{d}$ (restriction treatment) or $0.6 \mathrm{~kg} / \mathrm{d}$ (control treatment). From week 14 to 30 , the restricted group received the same amount of feed per $\mathrm{kg}$ body weight as was fed to the control group (compensatory phase).

All animals were fed individually and the diet contained (dry matter basis) lucerne (Medicago sativa) hay (18\%), maize silage (9\%), whole cottonseed (8\%), Eragrostis curvula hay $(13 \%)$ and a commercial energy-protein supplement (52\%). The diet contained $10.9 \mathrm{MJ} \mathrm{ME} / \mathrm{kg}$ dry matter and $176 \mathrm{~g}$ crude protein/kg dry matter. The same diet was used for both treatments, but the amount fed differed. Animals were fed daily (08:00), and intake was recorded on a daily basis. Body weight was recorded once weekly prior to feeding in the morning, and jugular blood samples were taken at the same time. Feed allocation required to sustain the desired rate of growth (i.e. 0.3 or $0.6 \mathrm{~kg} / \mathrm{d}$ ) was adjusted on a weekly basis, and calculated using the feed intake and body weight gain recorded during the preceding week.

Blood samples were collected into heparinised tubes and centrifuged (3000 x g for $12 \mathrm{~min}$ ) within $20 \mathrm{~min}$ of collection, and plasma was stored at $-20^{\circ} \mathrm{C}$ until analysis. Weekly plasma samples taken from weeks 13 to 24 were analyzed for progesterone concentrations. Plasma samples collected during weeks 0, 7, 13, 15, 17, 21 and 30 were analyzed for leptin and glucose concentrations. Plasma samples from weeks $0,7,13,15,17,19,21,23$ and 30 were analyzed for IGFBP-2 and IGFBP-3 concentrations. Plasma samples from weeks $0,13,15,17$ and 21 were analyzed for IGF-1 concentrations. For comparative purposes, analyses were also done for the corresponding treatment during the weeks representing the mean date of puberty for the control treatment (week 17) and the restriction treatment (week 21).

Plasma IGF-1 concentration was analyzed by a two-step sandwich type ELISA (Diagnostic Systems Laboratories Inc., USA). The inter and intra assay C.V. was 7.61 and $3.6 \%$ respectively. Concentrations of plasma glucose were determined by an enzymatic colorimetric assay (South African Institute for Medical Research, South Africa). The inter and intra assay C.V. was 3.44 and $1.52 \%$ respectively. Progesterone concentrations were determined using a direct solid-phase ELISA based on the competition principle (DRG ${ }^{\circledR}$ International, Inc., USA). The inter and intra assay C.V. was 9.1 and $4.2 \%$ respectively. Relative abundance of IGFBP was determined by SDS-PAGE and Western blotting (Fowlkes \& Serra, 1996) using biotinylated IGF-2 as ligand (Gropep, Adelaide, Australia). A horseradish catalyzed chemiluminescence method (Boehringer Mannheim GmbH, Germany) was used for detection of protein bands. Biotin-labeled calibration proteins (Boehringer Mannheim GmbH, Germany) were included for estimation of the molecular weights of protein bands, and a control sample was loaded with every gel to facilitate comparisons between batches. A double band at 39-42 kDa and a single band at $34 \mathrm{kDa}$ were assumed to be IGFBP-3 and IGFBP-2 respectively. Plasma leptin concentrations were determined by an ELISA assay based on the competition principle and microtiter plate separation (DRG ${ }^{\circledR}$ International, Inc., USA). The inter and intra assay C.V. was 5.36 and $4.85 \%$ respectively. It should be noted that the ELISA assays described above were based on human polyclonal antibodies, and caution should be exercised when comparing absolute values with those obtained by other methods, as Delavaud et al. (2000) have recently shown large differences between values obtained using a commercial 'multispecies' RIA kit and an ovine-specific leptin assay developed by them.

Progesterone concentrations were used to establish the presence of luteal activity. Puberty was taken to be the time at which ovulatory cycles began, and was defined as the week prior to the first time circulating concentrations of progesterone exceeded $1 \mathrm{ng} / \mathrm{ml}$ for two consecutive weeks (Werth et al., 1996).

Data were analyzed by one-factor repeated measures ANOVA with dietary treatment as the factor (SAS, 1987). Differences between treatments were analyzed by analysis of variance followed by the Duncan multiplerange test.

\section{Results}

Heifers in the control treatment reached puberty sooner $(\mathrm{P}<0.01)$ than the restricted group. The mean age at puberty was $43.8 \pm 0.75$ weeks for the control group (17 weeks after the beginning of the experimental period) and $47 \pm 0.63$ weeks for the restricted group ( 21 weeks after the beginning of the experimental period). Mean body weight at puberty was $256.3 \pm 5.22 \mathrm{~kg}$ and was not affected by treatment $(\mathrm{P}>0.05)$. Body weight was similar $(\mathrm{P}>$ 0.05 ) between treatments during the early (weeks 0 to 7) and late (weeks 26 to 30) stage of the experimental period (Figure 1), but differed from weeks 8 to $25(\mathrm{P}<0.05)$. 


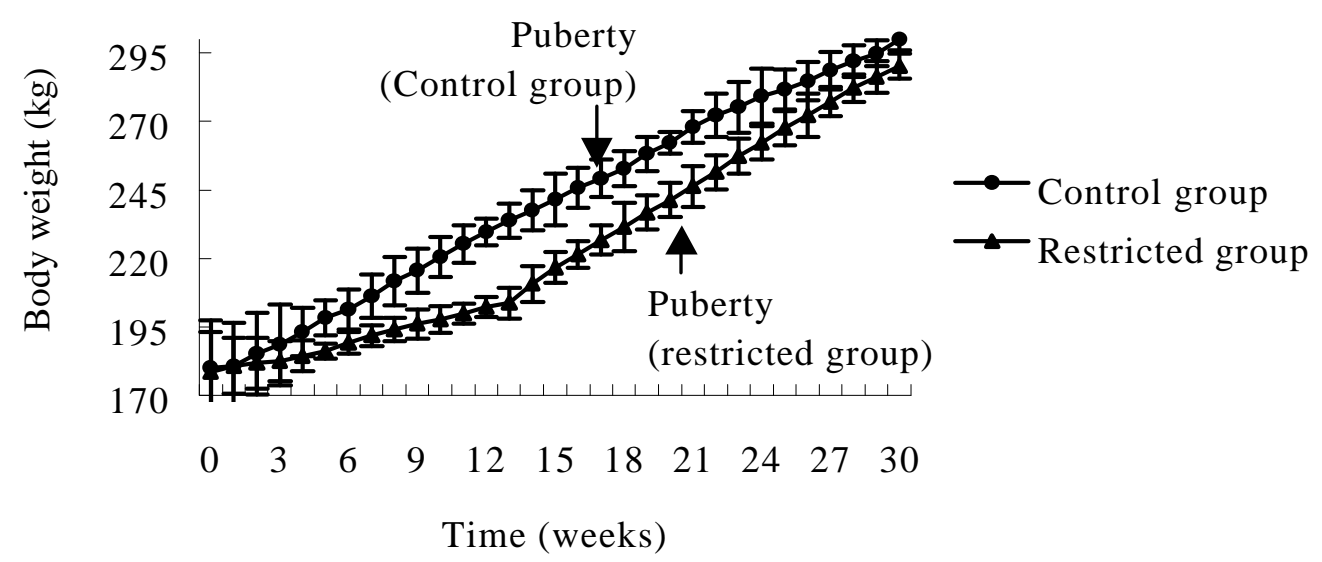

Figure 1 Body mass of heifers fed to maintain different growth rates. The control group was fed to maintain a growth rate of $0.6 \mathrm{~kg} / \mathrm{d}$ throughout the experimental period. The restricted group was fed to maintain a growth rate of $0.3 \mathrm{~kg} / \mathrm{d}$ during the first 13 weeks and received same amount of food as the control group for the remainder of the experimental period.

Growth rate differed between treatments $(\mathrm{P}<0.01)$ from week 0 to 25 (Figure 2). Body weight at the end of the trial was $294.1 \pm 9.3 \mathrm{~kg}$ and did not differ between the two treatments $(\mathrm{P}>0.05)$. Actual mean growth rates during the first 13 weeks of the experiment $(0.62 \mathrm{~kg} / \mathrm{d}$ and $0.33 \mathrm{~kg} / \mathrm{d})$ were similar to the target rates $(0.6 \mathrm{~kg} / \mathrm{d}$ and $0.3 \mathrm{~kg} / \mathrm{d}$ ) set for the two treatments (Figure 2). Mean growth rates following the restriction period were $0.58 \mathrm{~kg} / \mathrm{d}$ (control treatment) and $0.74 \mathrm{~kg} / \mathrm{d}$ (restriction treatment).

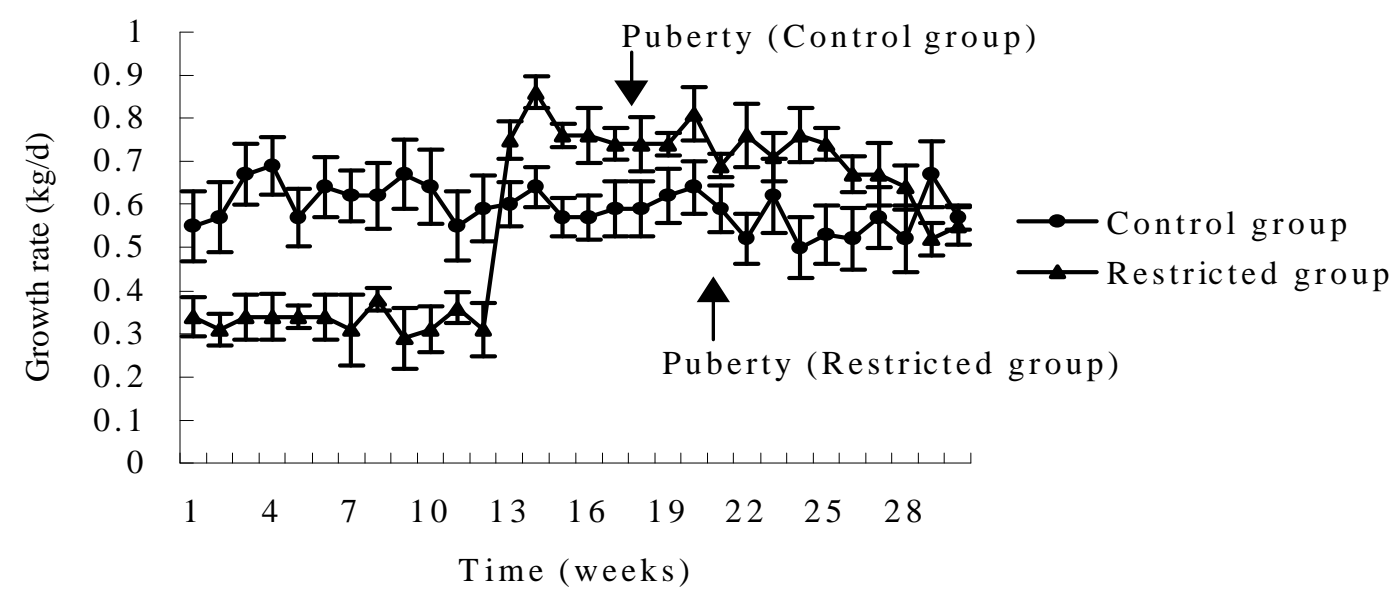

Figure 2 Growth rate in heifers fed to maintain different growth rates.

There were differences $(\mathrm{P}<0.05)$ in dry matter intake during the first 13 weeks of the trial as a result of the experimental protocol, however, no difference $(\mathrm{P}>0.05)$ was observed between the two dietary treatments after the restriction period. There were no differences $(\mathrm{P}>0.05)$ between dietary treatments for feed conversion ratio (Figure 3) during the first 13 weeks of the experiment, but during the following 14 weeks, a superior feed conversion ratio was observed for the restriction treatment $(\mathrm{P}<0.05)$. 


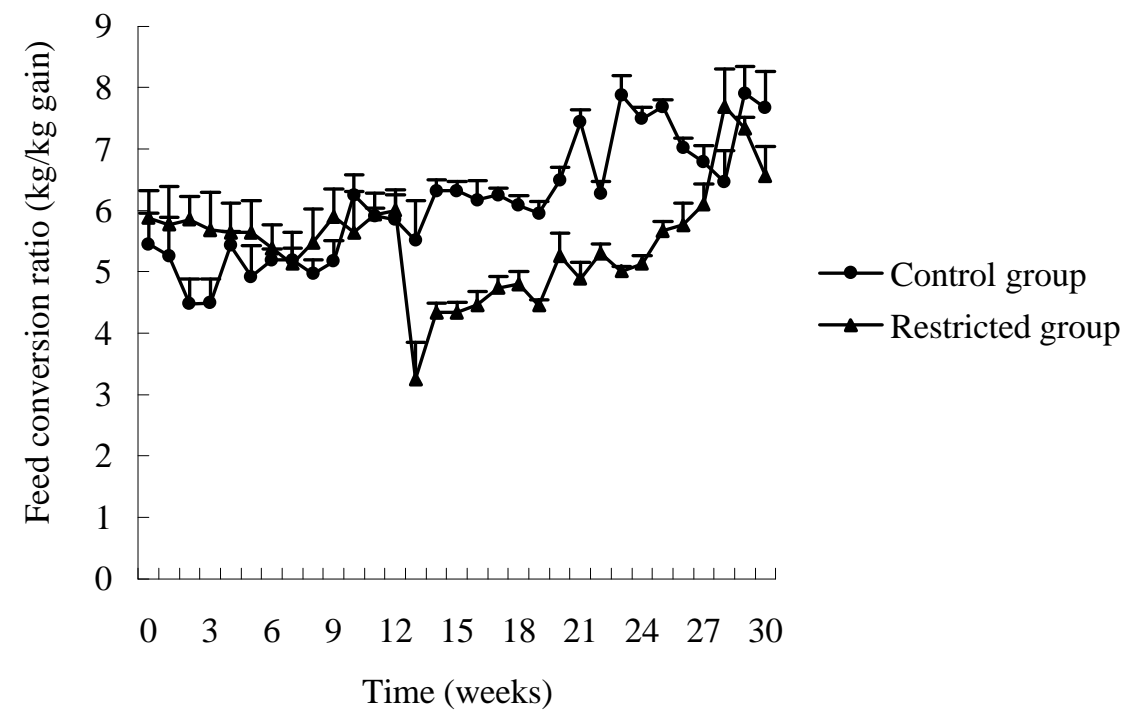

Figure 3 Feed conversion ratio in heifers fed to maintain different growth rates.

There were no treatment differences $(\mathrm{P}>0.05)$ for plasma concentration of leptin, IGF-1, IGFBP-3, IGFBP-2 and glucose at the beginning of the experiment. By the end of the restriction period (week 13) there were differences $(\mathrm{P}<0.01)$ between dietary treatments for plasma leptin, IGF-1, IGFBP-3 and glucose concentrations. There were no differences $(\mathrm{P}>0.05)$ in IGFBP-2 concentrations between treatments or sampling periods. Leptin concentration (Figure 4$)$ was higher $(\mathrm{P}<0.01)$ in the control group animals than in the restricted animals at weeks $7,13,15,17$ and 21 . Within the control group, there was a sequential increase $(\mathrm{P}<0.01)$ in plasma leptin concentration between weeks $0,7,13,15$ and 17 (puberty) respectively (Figure 4). In the restricted group, plasma leptin concentration was higher $(\mathrm{P}<0.01)$ during weeks 17,21 (puberty) and 30 than during weeks $0,7,13$ and 15, but no differences $(\mathrm{P}>0.05)$ were found between weeks 21 and 30 .

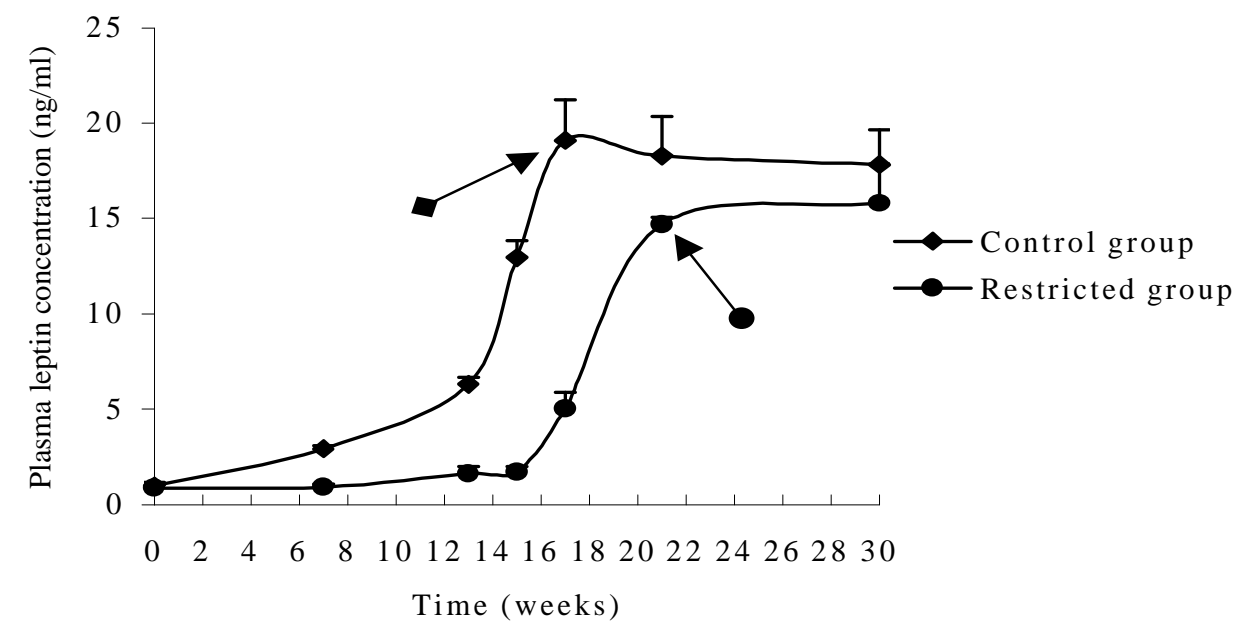

Figure 4 Plasma leptin concentration in heifers fed to maintain different growth rates (error bars denote s.e.m; arrows indicate mean age at puberty for the respective treatments).

Plasma IGF-1 concentration (Figure 5) was higher in the control group than in the restricted group at the end of the restriction phase (week 13). Plasma IGF-1 concentrations during the compensatory growth period (weeks 17-30) did not differ (P > 0.05) between treatments (Figure 5). Higher IGF-1 concentrations were observed in the restricted group during week 15, when growth rates were at their highest $(\mathrm{P}<0.01)$. Within the restricted group, IGF-1 concentration differed $(\mathrm{P}<0.01)$ between weeks $13 v s$. 15 , but not during the restriction period (weeks 0 vs. 13) or between weeks 15, 17 and 21 (puberty). Plasma IGF-1 concentration in the control group remained unchanged $(\mathrm{P}>0.05)$ during weeks 13,15 and 17 (puberty), but was lower $(\mathrm{P}<0.05)$ at week 0 than during the rest of the period. 


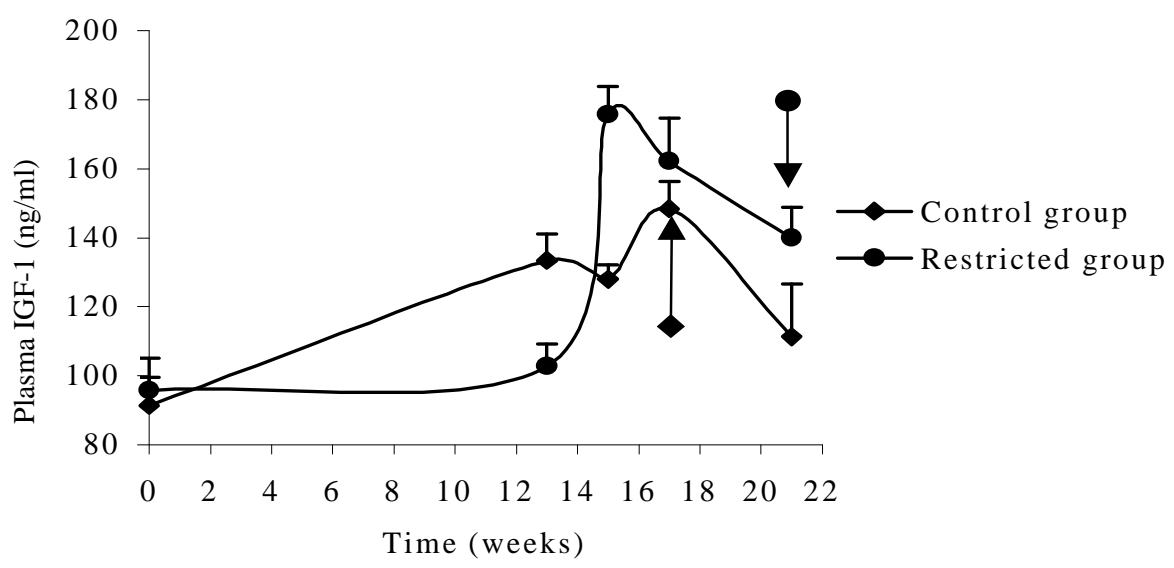

Figure 5 Plasma insulin-like growth factor-1 (IGF-1) concentration in heifers fed to maintain different growth rates (error bars denote s.e.m; arrows indicate mean age at puberty for the respective treatments).

Plasma IGFBP-3 concentrations (Figure 6) differed $(\mathrm{P}<0.05)$ between treatments at week 7, 13, 19 and 21. Within the control group, differences were observed between week 0 and weeks $7,13,15,17$ and 19 (P < 0.05), and were higher during weeks 15 and 17 (puberty) than during weeks 19,21, 23 and 30. Within the restricted group, differences $(\mathrm{P}<0.05)$ were observed between the restriction period and the compensatory growth period. Plasma IGFBP-3 concentration increased $(\mathrm{P}<0.05)$ during the compensatory period from week 13 until week 21 (mean age of puberty). After week 21, plasma IGFBP-3 concentration decreased $(\mathrm{P}<0.05)$ compared to that of the peripubertal period (weeks 17 to 21 ).

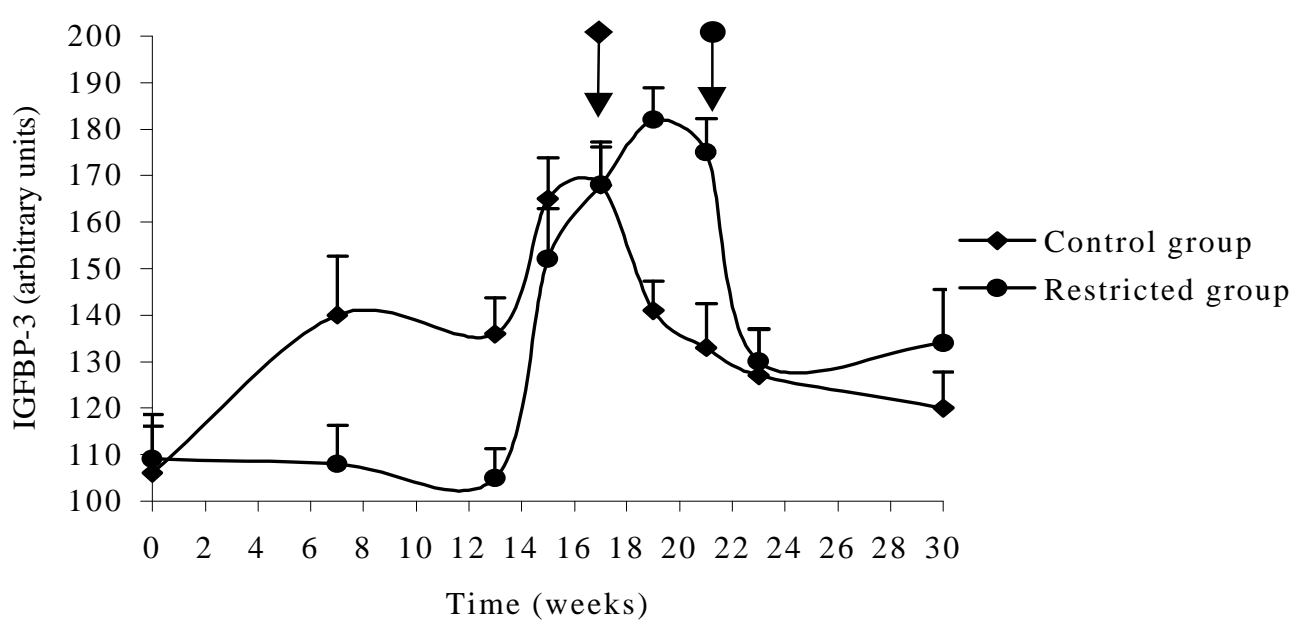

Figure 6 Plasma insulin-like growth factor binding protein-3 (IGFBP-3) concentration in heifers fed to maintain different growth rates (error bars denote s.e.m; arrows indicate mean age at puberty for the respective treatments).

Plasma glucose concentration (Figure 7) was higher $(\mathrm{P}<0.05)$ in the control group than the test group during the restriction period. During week 15 (compensatory period) higher $(\mathrm{P}<0.01)$ glucose concentrations were observed in the previously restricted group than in the control group, while there was no difference during weeks 17, 21 and 30. There were no differences in glucose concentration between weeks within the control group over the entire period, but in the restriction treatment glucose concentrations were higher during the compensatory phase than during the restriction phase $(\mathrm{P}<0.05)$. No differences were observed between weeks during the compensatory phase in previously restricted animals. 


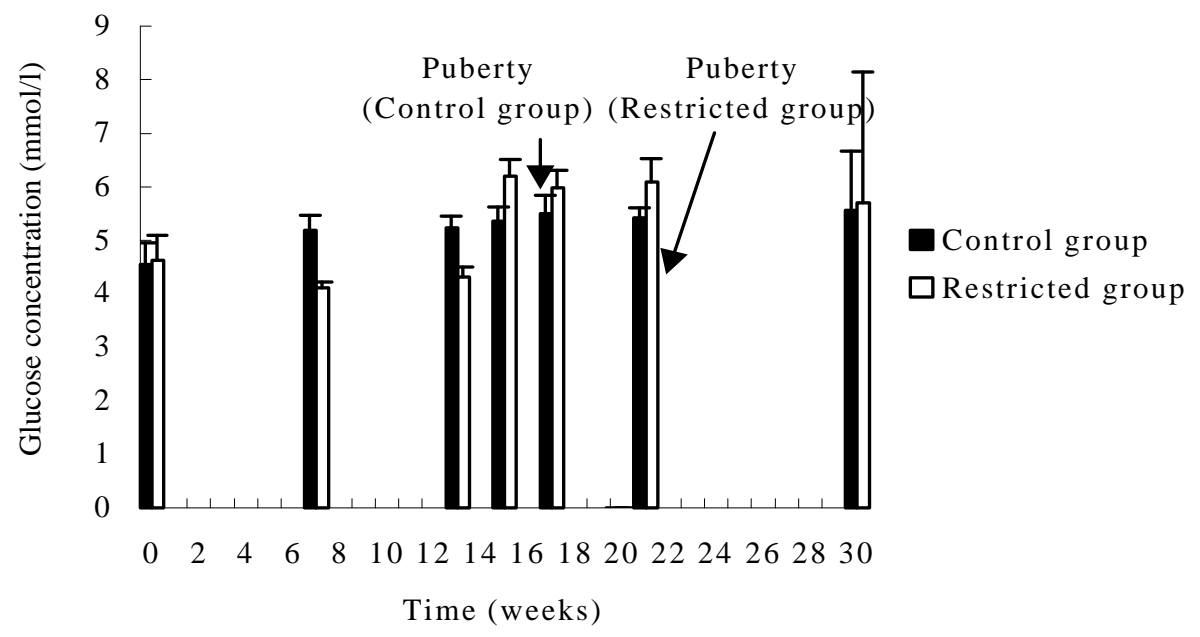

Figure 7 Plasma glucose concentrations in heifers fed to maintain different growth rates (error bars denote s.e.m).

\section{Discussion}

Although much research has been done to elucidate the mechanism of compensatory gain and its effects on mass and puberty, aspects of this phenomenon remain poorly understood. In particular, experiments where different planes of nutrition have been applied have given conflicting results in terms of animal performance, endocrine status and feed intake. Intake (Hornick et al., 1998), nutrient requirements (Sainz et al., 1995), composition of gain, energy utilization (Carstens et al., 1991), endocrine status (Yambayamba et al., 1996), diet digestibility (Murphy \& Loerch, 1994) and nutrient partitioning (Kamalzadeh et al., 1998) may all be changed by feed restriction, and contribute to compensatory growth effects in ruminants. In this experiment, the restricted group had a lower growth rate than the control group during the first 13 weeks (restriction period). During the following 17 weeks, the growth rate of the previously restricted animals was greater than that of the control group (compensatory growth). Growth rate was greater during the first four weeks of the re-alimentation period than during the following 13 weeks for animals in the restricted group (Figure 2). Several studies have shown a similar pattern, and this was attributed to differences in the ratio of protein : fat deposition during initial $v s$. subsequent weight gain (Wright \& Russel, 1991; Sainz et al., 1995; Hornick et al., 1998), and to differences in the efficiency of energy and protein utilization (Fox et al., 1972). Growth and development of various organs is affected by feed restriction and subsequent re-feeding (e.g. kidney, liver and gastrointestinal tract), and this could also explain much of the differences. Changes in gut-fill and energy content of gain are considered to be the most important cause of compensatory growth (Carstens et al., 1991; Hornick et al., 1998).

IGF-1 promotes cell differentiation and proliferation, and feed restriction is generally associated with low plasma IGF-1 concentrations (Breier \& Gluckman, 1991), as was the case in the present study (Figure 5). Yambayamba et al. (1996) and Hornick et al. (1998) found that growth rate was positively associated with serum IGF-1 concentration during compensatory growth. Van den Brande (1986) suggested that rapid growth rate during compensatory growth is caused by a change in tissue sensitivity to IGF-1. In this study, plasma IGF-1 and IGFBP-3 concentrations in both treatments followed a pattern similar to that of growth rate. Plasma IGF-1 and IGFBP-3 concentrations were higher in the restricted group than in the control group during the early compensatory phase. Higher concentrations of GH during the early compensatory stage (Yambayamba et al., 1996), changes in GH receptor activity (Davis, 1988) and interactions between IGF-1 and IGFBP-3 (Spicer \& Chamberlain, 1999) could explain compensatory growth effects in young heifers. Riedl et al. (1998), working with renal transplanted peripubertal children, found that catch-up weight after surgery was better related to an increase in the ratio of IGF-1 to IGFBP-3 than to the individual concentrations of IGF-1 or IGFBP-3.

The higher average daily gain in the control heifers resulted in attainment of puberty at a younger age than in restricted animals, but body weight at puberty was similar for both treatments. Several authors (Menge et al., 1960; Short et al., 1971; Yelich et al., 1996) have shown that there is an inverse correlation between the level of intake and age at puberty in heifers. Nutritional status affects circulating concentrations of IGF-1, as discussed above, and this may affect not only growth rate, but other physiological functions. IGF-1 stimulates mitogenesis and steroidogenesis in ovarian granulosa and thecal cells (Stewart et al., 1996). Spicer \& Chamberlain (1999) found that IGFBP-3 inhibited the mitogenic effects of IGF-1 in granulosa cells in cattle ovaries and inhibited estradiol production, but did not decrease progesterone concentration. Furthermore, a change in the ratio of IGFBP3: IGF-1 produced different effects on steroidogenesis and cell division, suggesting that IGFBP-3 has regulatory 
effects on reproduction. In the present experiment, concentrations of IGFBP-3 increased and peaked at puberty for both treatments, even though puberty occurred at different ages. In contrast, concentrations of IGF-1 peaked at the point of maximum growth rate in the previously restricted animals, and in neither treatment was there a clear relationship with age at puberty. This would have resulted in a change in the ratio between IGFBP-3 and IGF-1, and suggests that variation in IGF-1: IGFBP-3 ratio could possibly mediate the time to reach puberty. Results obtained by Jones et al. (1991), Granger et al. (1989) and Yelich et al. (1996) differ from results obtained in the present experiment in terms of association between puberty and IGF-1 concentration. These authors found that IGF-1 increased before puberty, independent of dietary treatment. While the reason for the differing results is unknown, it is suggested that the ratio between IGF-1 and IGFBP-3 would be a more valid parameter for future studies, as the physiological effects of IGF-1 are known to be affected by binding to IGFBP-3 (Murphy, 1998).

Spicer \& Chamberlain (1999) have shown that IGFBP-2 is produced in ovarian follicular cells and can modulate the availability of IGF-1 in different ways, acting via endocrine, paracrine and autocrine pathways during follicular development. In this experiment peripheral concentrations of IGFBP-2 were similar between treatments, suggesting that IGFBP-2 did not affect the availability of IGF-1 in the peripheral circulation.

Animals fed restricted diets at different stages and subject to differences in the severity of growth restriction had different amounts of adipose tissue (Sainz et al., 1995). Although adiposity was not measured in this trial, the differences in weight gain would be expected to be related to differences in adiposity. The importance of a critical amount of fat for attainment of puberty is well-known (Frisch \& McArthur, 1974; Snow et al., 1989; Frisch, 1994), suggesting that an interaction exits between adipose tissue and the hypothalamic-pituitary-gonadal axis to ensure that sufficient energy supplies for pregnancy and lactation are deposited before commencement of reproductive cycles. Leptin is a recently discovered protein that is mainly synthesized in adipose tissue (Considine $\&$ Caro, 1996). The rate of leptin production is directly related to the weight of body fat in several species (Prolo et al., 1998), including cattle (Chilliard et al., 1998) and sheep (Delavaud et al., 2000). Chehab et al. (1996) reported that prepuberal female mice injected with leptin reached puberty nine days before untreated mice and suggested that leptin acts as signal for initiation of puberty, but concluded that this is not the only signal involved in the onset of puberty. Although circulating leptin appears to correlate with the amount of adipose tissue, changes in energy intake and growth rate can alter serum leptin concentration (Foster \& Nagatani, 1999; Delavaud et al., 2000). Amstalden et al. (1999) found that fasting $(56 \mathrm{~h})$ in prepubertal heifers reduced leptin mRNA expression in adipose tissue by $45 \%$ and IGF- 1 plasma concentration by $50 \%$. It was suggested that these two factors serve as metabolic signals to the reproductive axis. A strong association between serum concentration of leptin and IGF-1, IGF-2 and IGFBP-3 in lean but not in fat humans was found by Seck et al. (1998). In the present experiment, plasma leptin concentrations increased until puberty in both treatments even though the date of puberty differed. Foster \& Nagatani (1999) suggested that leptin affects the time taken to reach puberty by its interaction with IGF-1 as well through glucose availability, however, Nyomba et al. (1999), working with lean and obese human females, found that leptin was better related to IGFBP-3 concentration and body mass index than to IGF-1 or glucose concentration. The results of the present experiment confirm the findings of Nyomba et al. (1999).

Yambayamba et al. (1996) found that plasma glucose concentration in beef heifers was higher after restriction than during restriction; similar results were obtained in the present study. Glucose availability is also thought to be a metabolic signal involved with the control of GnRH secretion, and glucose availability has been shown to be associated with LH secretion in sheep (Bucholtz et al., 1996) and cattle (Stewart et al., 1995). Furthermore, Foster \& Nagatani (1999) showed that the concentration of glucose increases during puberty. In this experiment, plasma glucose concentration did not change at puberty for either treatment; however, differences between treatments were found after the restriction period. Reports on the relationship between plasma glucose concentration and luteal activity are contradictory (Richards et al., 1989; Rutter \& Manns, 1987), and no clear mechanism has yet been identified.

\section{Conclusion}

It was concluded that concentrations of glucose, IGF-1 and IGFBP-3 are affected by nutritional restriction and repletion, and may contribute to the endocrine regulation of compensatory growth. Early puberty achieved by accelerated prepubertal growth results in earlier attainment of high concentrations of IGF-1, IGFBP-3 and leptin. It is suggested that the increased concentrations of leptin and IGFBP-3 during pubertal development can act as physiological signals for the onset of puberty. The management and manipulation of these endocrine factors may be useful in future to induce early puberty in younger and/or thinner animals and to reduce the interval between calving and conception in ruminants. 


\section{Acknowledgements}

The assistance of H.T. Groeneveld and M.J. Van der Linde with statistical analyses, and that of E.J. Mulder with laboratory analyses is gratefully acknowledged.

\section{References}

Amstalden, M., Garcia, M.R., Williams, S.W., Stanko, R.L., Nizielski, S.E., Keisler, D.H. and Williams, G.L., 1999. Leptin gene expression is acutely responsive to short-term fasting in prepubertal heifers: relationship to circulating leptin, insulin-like growth factor-1, and luteinizing hormone pulsatility. Biology of Reproduction 60, 122.

Breier, B.H. and Gluckman, P.D., 1991. The regulation of postnatal growth: nutritional influence on endocrine pathways and function of the somatotrophic axis. Livest. Prod. Sci. 27, 77-89.

Bucholtz, D.C., Vidwans, N.M., Herbosa, C.G., Schillo, K.K. and Foster, D.L., 1996. Metabolic interfaces between growth and reproduction. V. Pulsatile luteinizing hormone secretion is dependent on glucose availability. Endocrinology 137, 601-607.

Buskirk, D.D., Faulkner, D.B. and Ireland, F.A., 1995. Increased post-weaning gain of beef heifers enhances fertility and milk production. J. Anim. Sci. 73, 937-946.

Carstens, G.E., Johnson, D.E., Ellenberger, M.A. and Tatum, J.D., 1991. Physical and chemical composition of gain in beef steers exhibiting normal and compensatory growth in beef steers. J. Anim. Sci. 69, 3251-3260.

Chehab, F.F., Lim, M.E. and Lu, R., 1996. Correction of the sterility effect in homozygous obese female mice by treatment with the human recombinant leptin. Nature Genetics 12, 318-320.

Chilliard, Y., Bocquier, F., Delavaud, C, Guerre-Millo, M., Bonnet, M., Martin, P., Faulconnier, Y. and Ferlay, A., 1998. Leptin in ruminants: effects of species, breed, adiposity, photoperiod, b-agonists and nutritional status. In: Proceedings of the Cornell nutrition conference for feed manufacturers. Department of Animal Science and Division of Nutritional Sciences, Cornell University, USA, pp 65-74.

Considine, R.V. and Caro, J.F., 1996. Leptin in humans: current progress and future directions. Clin. Chem. 42, 843-844.

Davis, S.L., 1988. Recent concepts in regulation of growth by GH and IGF. J. Anim. Sci. 66 (Suppl. 3), 84.

Delavaud, C., Bocquier, F., Chilliard, Y., Keisler, D.H., Gertler, A. and Kann, G., 2000. Plasma leptin determination in ruminants: effect of nutritional status and body fatness on plasma leptin concentration assessed by a specific RIA in sheep. J. Endocrinology 165, 519-526.

Foster, D.L. and Nagatani, S., 1999. Physiological perpectives on leptin as a regulator of reproduction: role in timing puberty. Biol. Reprod. 60, 205-215.

Fowlkes, J.L. and Serra, D., 1996. A rapid, non-radioactive method for the detection of insulin-like growth factor binding proteins by Western ligand blotting. Endocrinology 137, 5751-5754.

Fox, D.G., Johnson, R.R., Preston, R.L., Dockerty, T.R. and Klosterman, E.W., 1972. Protein and energy utilization during compensatory growth in beef cattle. J. Anim. Sci. 34, 310-322.

Frisch, R.E. and McArthur, J.W., 1974. Menstrual cycles: fatness as a determinant of minimum weight for height necessary for their maintenance or onset. Science 185, 949-951.

Frisch, R.E., 1994. The right weight: body fat, menarche and fertility. Proc. Nutr. Soc. 53, 113-129.

Granger, A.L., Wyatt, W.E., Craig, W.M., Thompson, D.L. and Hembry, F.G., 1989. Effects of breed and wintering diet on growth, puberty and plasma concentration of growth hormone and insulin-like growth factor-1 in heifers. Dom. Anim. Endo. 6, 253-262.

Hornick, J.L., van Eenaeme, C., Diez, M., Minet, V. and Istasse, L., 1998. Different periods of feed restriction before compensatory growth in Belgian Blue bulls: II Plasma metabolites and hormones. J. Anim. Sci. 76, 260-271.

Jones, E.J., Armstrong, J.D. and Harvey, R.W., 1991. Changes in metabolites, metabolic hormones, and luteinizing hormone before puberty in Angus, Bradford, Charolais and Simmental heifers. J. Anim. Sci. 69, 16071615.

Kamalzadeh, A., Koops, W.J. and Van Bruchem, J., 1998. Feed quality restriction and compensatory growth in growing sheep: modeling changes in body dimensions. Livest. Prod. Sci. 53, 57-67.

Koong, L.J., Nienaber, J.C., Pekas, J.C. and Yen, J.T., 1982. Effects of plane of nutrition on organ size and fasting heat production in pigs. J. Nutr. 112, 1638-1642.

Menge, A.C., Mares, S.E., Tyler, W.J. and Casida, L.E., 1960. Some factors affecting age at puberty and the first 90 days of lactation in Holstein heifers. J. Dairy Sci. 29: $602-605$.

Murphy, T.A. and Loerch, S.C., 1991. Effects of restricted feeding of growing steers on performance, carcass characteristics and composition. J. Anim. Sci. 72, 2497-2505. 
Murphy, L.J., 1998. Insulin-like growth factor binding proteins: functional diversity or redundancy? J. Mol. Endo. 21, 97-107.

Nyomba, B.L.G., Johnson, M., Berard, L. and Murphy, L.J., 1999. Relationship between serum leptin and the insulin-like growth factor-1 system in humans. Metabolism: Clinical and Experimental 48, 840-844.

Prolo, P., Wong, M.L. and Licinio, J., 1998. Leptin. Int. J. Biochem. and Cell Biol. 30, 1285-1290.

Richards, M.W., Wettemann, R.P. and Schoenemann, H.M., 1989. Nutritional anestrous in beef cows: concentrations of glucose and nonesterified fatty acids in plasma and insulin in serum. J. Anim. Sci. 67, 2354-2362.

Richards, M.W., Wettemann, R.P., Spicer, L.J., and Morgan, G.L., 1991. Nutritional anestrus in beef cows: effects of body condition and ovariectomy on serum luteinizing hormone and insulin-like growth factor-1. Biology of Reproduction 44, 961-966.

Riedl, S., Lebl, J., Kluge, M., Kreisiger, J., Simkova, E., Kohlhauser, C., Balzar, E. and Frisch, H., 1998. Treatment of peripubertal children after renal transplantation (RTX) with recombinant human growth hormone: auxological data and effects on insulin-like growth factor-1 (IGF-1) and IGF-binding protein-3 (IGFBP-3) during 24 months. J. Pediatric Endocrin. and Metab. 11, 713-718.

Rutter, L.M. and Manns, J.G., 1987. Hypoglycemia alters pulsatile luteinizing hormone secretion in the postpartum beef cow. J. Anim. Sci. 64, 479-488.

Sainz, R.D., De la Torre, F. and Oltjen, J.W., 1995. Compensatory growth and carcass quality in growth-restricted and refed beef steers. J. Anim. Sci. 73, 2971-2979.

SAS, 1987. SAS User's guide: Statistics, version 6. SAS institute Inc., Cary, NC, USA.

Seck, T., Englaro, P., Blum, W.F., Scheidt-Nave, C., Rascher, W., Ziegler, R. and Pfeilschifter, J., 1998. Leptin concentrations in serum from a randomly recruited sample of 50 to 80-years-old men and women: positive association with plasma insulin-like growth factors (IGFs) and IGF-binding proteins-3 in lean, but not in obese individuals. European J. Endocrinology 138, 70-75.

Sejrsen, K., Hubert, J.T., Tucker, H.A. and Akers, R.M., 1982. Influence of nutrition on mammary development in pre- and postpubertal heifers. J. Dairy Sci. 65, 793-800.

Short, R.E. and Bellows, R.A., 1971. Relationship among weight gains, age at puberty and reproductive performance in heifers. J. Anim. Sci. 32, 127-131.

Snow, R.C., Barbieri, R.L. and Frisch, R.E., 1989. Estrogen 2-hydroxylase oxidation and menstrual function among elite oars women. J. Clinical Endocrin. Metab. 69, 369-376.

Spicer, L.J. and Chamberlain, C.S., 1999. Insulin-like growth factor binding protein-3: its biological effect on bovine granulosa cells. Dom. Anim. Endo. 16, 19-29.

Stewart, R.E., Spicer, L.J., Hamilton, T.D. and Keefer, B.E., 1995. Effects of insulin-like growth factor -1 and insulin on proliferation and on basal and luteinizing hormone-induced steroidogenesis of bovine thecal cells: involvement of glucose and receptors for insulin-like growth factor-1 and luteinizing hormone. J. Anim. Sci. 73, 3719-3731.

Stewart, R.E., Spicer, L.J., Hamilton, T.D., Keefer, B.E., Dawson, L.J., Morgan, G.L. and Echternkamp, S.E., 1996. Levels of insulin-like growth factor (IGF) binding proteins, luteinizing hormone and IGF receptors, and steroids in dominants follicles during the first follicular wave in cattle exhibiting regular estrous cycles. Endocrinology 137, 2842-2850.

Van den Brande, J.L., 1986. Catch-up growth. Possible mechanism. Acta Endocrinology 113, 13-19.

Werth, L.A., Whittier, J.C., Azzam, S.M., Deutscher, G.H., and Kinder, J.E., 1996. Relationship between circulating progesterone and conception at the first postpartum estrus in young primiparous beef cows. J. Anim. Sci. 74, 616-619.

Wright, I.A. and Russel, A.J.F., 1991. Changes in the body composition of beef cattle during compensatory growth. Anim. Prod. 52, 105-114.

Yambayamba, E.S.K., Price, M.A. and Foxcroft, G.R., 1996. Hormonal status, metabolic changes and resting metabolic rate in beef heifers undergoing compensatory growth. J. Anim. Sci. 74, 57-69.

Yelich, J.V., Wetterman, R.P., Marston, T.T. and Spicer, L.J., 1996. Luteinizing hormone, growth hormone, insulin-like growth factor, insulin and metabolites before puberty in heifers fed to gain at two rates. Dom. Anim. Endocrin. 13, 325-338. 